\title{
AIDS and non-AIDS diffuse large B-cell lymphomas express different antigen profiles
}

\author{
Rashna Madan ${ }^{1, *}$, Robert Gormley ${ }^{1, *}$, Alina Dulau ${ }^{1, *}$, Dongsheng $\mathrm{Xu}^{1}$, Daniel Walsh ${ }^{1}$, \\ KH Ramesh ${ }^{1}$, Linda Cannizaro ${ }^{1}$, Ecaterina F Tamas ${ }^{2}$, Pankaj Kumar ${ }^{3}$, Joseph Sparano ${ }^{3}$, \\ Aaron LeValley ${ }^{4}$, Xiaonan Xue ${ }^{4}$, Pritish K Bhattacharyya ${ }^{5}$, Harry L Ioachim ${ }^{2}$ \\ and Howard Ratech ${ }^{1}$
}

${ }^{1}$ Department of Pathology, Albert Einstein College of Medicine/Montefiore Medical Center, Bronx, NY, USA; ${ }^{2}$ Department of Pathology, Lenox Hill Hospital, New York, NY, USA; ${ }^{3}$ Department of Oncology, Albert Einstein College of Medicine/Montefiore Medical Center, Bronx, NY, USA; ${ }^{4}$ Department of Epidemiology and Population Health, Albert Einstein College of Medicine, Bronx, NY, USA and ${ }^{5}$ Department of Pathology, Hackensack Medical Center, Hackensack, NJ, USA

\begin{abstract}
Based on gene expression profiling, diffuse large B-cell lymphomas arising in immunocompetent patients can be divided into germinal center and activated B-cell types. Since little is known about acquired immunodeficiency syndrome associated diffuse large B-cell lymphomas, we tested whether the protein expression of germinal center and activated B-cell markers differed between acquired immunodeficiency syndrome (AIDS) vs non-AIDS diffuse large B-cell lymphomas. We immunohistochemically stained tissue microarrays of 39 de novo diffuse large B-cell lymphomas: 12 AIDS associated and 27 non-AIDS, with germinal center (BCL6, CD10, CyclinH) and activated B-cell markers (MUM1, CD138, PAK1, CD44, BCL2). We scored each case for percent positive cells $(0-19 \%=0 ; 20-49 \%=1 ; 50-100 \%=2)$. The activated B-cell and germinal center summation scores of each case were used as $(x, y)$ coordinate data points to construct two-dimensional contour-frequency plots. The contour plot of non-AIDS diffuse large B-cell lymphomas showed two distinct clusters: a cluster with a high germinal center phenotype (cluster 1 ) and a cluster with a high activated B-cell phenotype (cluster 3). In contrast, the AIDS-related diffuse large B-cell lymphomas formed a single aggregate (cluster 2) ( $P=0.02$, Fisher exact test). When the contour plots of the AIDS-related and the non-AIDS cases were superimposed, cluster 2 of the AIDS cases expressed an intermediate germinal center/activated B-cell phenotype compared to clusters 1 and 3 of the non-AIDS diffuse large B-cell lymphomas. Our results confirm that non-AIDS diffuse large B-cell lymphomas segregate into two groups with either germinal center or activated B-cell phenotype. We report the new finding that the AIDS status of the patient predicts the immunophenotype of the diffuse large B-cell lymphomas.
\end{abstract}

Modern Pathology (2006) 19, 438-446. doi:10.1038/modpathol.3800493; published online 27 January 2006

Keywords: AIDS; diffuse large B-cell lymphoma; germinal center; activated B-cell; gene expression; immunophenotype

Diffuse large B-cell lymphomas are mature B-cell malignancies with homogeneous morphology but heterogeneous clinical behavior. Germinal center or activated B-cell expression profiles can predict good or bad clinical prognosis. ${ }^{1-4}$ Although gene and protein signatures of diffuse large B-cell lymphomas have been shown to be clinically relevant in immunocompetent patients, they have not yet been tested in patients with the acquired immunodefi-

Correspondence: Dr H Ratech, MD, Department of Pathology, Albert Einstein College of Medicine/Montefiore Medical Center, 111 E 210th Street, Silver Zone, North 4, Bronx, NY 10467, USA. E-mail: hratech@montefiore.org

*These three authors equally contributed to this work.

Received 15 June 2005; revised and accepted 11 August 2005; published online 27 January 2006 ciency syndrome (AIDS). Therefore, we analyzed germinal center and activated B-cell protein markers in a panel of AIDS and non-AIDS lymphomas. We also describe a novel method for displaying immunohistochemical expression data using twodimensional contour-frequency plots.

\section{Materials and methods}

Lymphoma Samples

We performed a retrospective study of 56 diffuse large B-cell lymphomas (23 AIDS-related and 33 non-AIDS) that were retrieved from the archives of Montefiore Medical Center, Bronx, NY; Lenox Hill Hospital, New York, NY; and Hackensack Medical 
Center, Hackensack, NJ. In all, 17 cases were excluded on the basis of prior therapy or history of preceding low-grade lymphoma. The remaining $39 \mathrm{de}$ novo diffuse large B-cell lymphomas were classified as either centroblastic or immunoblastic ( $>90 \%$ immunoblasts) according to World Health Organization morphologic criteria. ${ }^{5}$ We discriminated between a diagnosis of variant Burkitt lymphoma vs diffuse large B-cell lymphomas on the basis of high Ki-67 proliferation index and/or the presence of $c$-myc translocation, which was determined by fluorescent in situ hybridization (FISH) on paraffin sections.

\section{Clinical Information}

We collected clinical data from medical records or from the patient's physician: sex, International Prognostic Index (IPI) score (age, serum lactic dehydrogenase (LDH), nodal vs extra nodal presentation, performance status, stage), ${ }^{6}$ AIDS status, and overall survival. This study was performed according to Institutional Review Board guidelines of the participating institutions.

\section{Tissue Microarrays}

Tissue microarrays were constructed from formalinfixed, paraffin-embedded tissue blocks using a manual tissue arrayer (Beecher Instruments, Silver Spring, MD, USA). To ensure adequate sampling, each case was represented in triplicate using $1.0 \mathrm{~mm}$ cores. Reactive tonsil, liver, and kidney were also included as controls.

\section{Immunohistochemistry}

We stained lymphoma samples with a comprehensive panel of germinal center (BCL6, CD10, Cyclin $\mathrm{H})$ and activated B-cell markers (MUM1, CD138, PAK1 (p21 activated kinase 1), CD44, BCL2). In addition, we determined T- or B-cell lineage and the Ki-67 proliferative index. We used a modified avidin-biotin immunohistochemical technique, as noted in Table 1. The following immunostains were performed using the DAKO Autostainer: CD138, CD3 (T-cell) and CD20 (B-cell). Tonsil was used as a control for MUM1, BCL2, BCL6, CD10, CD3, CD20, CD138, and Ki67; testes for Cyclin H; and breast carcinoma for PAK1.

Each immunostain was evaluated in a semiquantitative manner for percent positive cells: $0=0$ $19 \%, 1=20-49 \%$, and $2=50-100 \%$. Stain intensity was not measured. Only nuclear staining was considered for MUM1, BCL6 and Ki-67. The percent of Ki-67-positive cells was scored as: $0=0-49 \%$, $1=50-79 \%$, and $2=80-100 \%$.

Table 1 Antibodies

\begin{tabular}{|c|c|c|c|c|c|c|}
\hline $1^{\circ}$ Antibody & Source & Clone & Dilution & Specificity & Retrieval & Detection system \\
\hline${\text { BCL } 2^{\mathrm{a}}}$ & Mouse monoclonal & 124 & $1: 100$ & Not specified & $\mathrm{HipH}^{\mathrm{b}}$ & Envision $^{\mathrm{TM}}$ monoclonal $^{\mathrm{c}}$ \\
\hline BCL6 $^{\text {a }}$ & Mouse monoclonal & PG-B6p & $1: 20$ & $\begin{array}{l}\text { Human, cow, rabbit, } \\
\text { rat, sheep, swine }\end{array}$ & $\mathrm{HipH}^{\mathrm{b}}$ & Envision $^{\mathrm{TM}}$ monoclonal $^{\mathrm{c}}$ \\
\hline $\mathrm{CD}^{\mathrm{d}}$ & Mouse monoclonal & F2.2.38 & $1: 20$ & Not specified & $\mathrm{ER}^{\mathrm{e}}$ & Envision $^{\mathrm{TM}}$ monoclonal $^{\mathrm{c}}$ \\
\hline $\mathrm{CD} 10^{\mathrm{f}}$ & Mouse monoclonal & Not specified & $1: 20$ & Not specified & $\mathrm{HipH}^{\mathrm{b}}$ & Envision $^{\mathrm{TM}}$ monoclonal $^{\mathrm{c}}$ \\
\hline $\mathrm{CD} 20^{\mathrm{g}}$ & Mouse monoclonal & L26 & $1: 50$ & Not specified & $\mathrm{ER}^{\mathrm{e}}$ & Envision $^{\mathrm{TM}}$ monoclonal $^{\mathrm{c}}$ \\
\hline $\mathrm{CD} 44^{\mathrm{a}}$ & Mouse monoclonal & DF1485 & $1: 40$ & Not specified & $\mathrm{TR}^{\mathrm{h}}$ & Envision $^{\mathrm{TM}}$ monoclonal $^{\mathrm{C}}$ \\
\hline $\mathrm{CD} 138^{\mathrm{a}}$ & Mouse monoclonal & B-B4 & $1: 500$ & Not specified & $\mathrm{ER}^{\mathrm{e}}$ & Envision $^{\mathrm{TM}}$ monoclonal $^{\mathrm{C}}$ \\
\hline Cyclin $\mathrm{H}^{\mathrm{i}}$ & Mouse monoclonal & D-10 & $1: 100$ & Human, mouse, rat & $\mathrm{ER}^{\mathrm{e}}$ & LSAB2 system ${ }^{\mathrm{a}}$ \\
\hline Ki- $67^{\mathrm{C}}$ & Mouse monoclonal & MIB-1 & $1: 50$ & $\begin{array}{l}\text { Human, cow, sheep, } \\
\text { swine, horse, dog }\end{array}$ & $\mathrm{TR}^{\mathrm{h}}$ & Envision $^{\mathrm{TM}}$ monoclonal $^{\mathrm{C}}$ \\
\hline MUM1/IRF $4^{\mathrm{i}, \mathrm{j}}$ & Goat polyclonal & $\mathrm{M}-17$ & $1: 200$ & Human, mouse, rat & $\mathrm{TR}^{\mathrm{h}}$ & Goat ABC staining system ${ }^{\mathrm{i}}$ \\
\hline PAK $1^{\mathrm{k}}$ & Rabbit polyclonal & Not specified & $1: 50$ & $\begin{array}{l}\text { Human, mouse, rat, } \\
\text { monkey, guinea pig }\end{array}$ & $\mathrm{ER}^{\mathrm{e}}$ & Envision $^{\mathrm{TM}}$ polyclonal $^{\mathrm{C}}$ \\
\hline
\end{tabular}

4-6 $\mu \mathrm{m}$ thick sections of formalin-fixed, paraffin-embedded tissue blocks were deparaffinized, rehydrated, blocked with $3 \%$ hydrogen peroxide, appropriately retrieved, incubated with the primary antibody, followed with by the secondary detection system with either diaminobenzidine (DAB) for the LSAB2 system or DAB plus (Dako, Carpintaria, CA, USA) for the Envision ${ }^{\mathrm{TM}}$ system. $^{2}$

${ }^{\mathrm{a}}$ Serotec, Oxford, UK.

${ }^{\mathrm{b}}$ High pH Target Retrieval Solution.

${ }^{\mathrm{C}}$ Dako, Carpinteria, CA, USA.

$\mathrm{d}_{\text {Biogenex, San Ramon, CA, USA. }}$

${ }^{\mathrm{e}}$ Epitope Retrieval Solution.

${ }^{\mathrm{f}}$ Cell Marque, Hot Springs, AK, USA.

$\mathrm{g}_{\text {Zymed, San Francisco, CA, USA. }}$

${ }^{\mathrm{h}}$ Target Retrieval Solution.

${ }^{\text {i }}$ Santa Cruz Biotechnology, Santa Cruz, CA, USA.

${ }^{j}$ We used a polyclonal antibody for MUM1/IRF4 commercially available at the time of our study which has been compared to the monoclonal antibody with generally superimposable results. ${ }^{34}$

${ }^{\mathrm{k}}$ Cell Signal, Beverly, MA, USA. 


\section{FISH for c-myc Translocation}

Translocations involving the $c$-myc locus were detected with an LSI MYC Dual Color, Break Apart Rearrangement probe (Vysis Inc., Downer's Grove, IL, USA), comprising two probes that flank opposite sides of the region $3^{\prime}$ of $M Y C$ (one probe begins upstream of the $5^{\prime}$ end of the $M Y C$ locus (extends $260 \mathrm{~kb}$ towards centromere) and the other starts $1 \mathrm{Mb}$ $3^{\prime}$ of the $M Y C$ locus (extends $400 \mathrm{~kb}$ towards the telomere)). We performed the procedure on formalin-fixed, paraffin-embedded tissue microarray sections according to the manufacturer's directions with minor modifications: deparaffinization, Hemo-De clearing agent, $15 \mathrm{~min}$; pretreatment, sodium thiocyanate, $20 \mathrm{~min}$ at $80^{\circ} \mathrm{C}$; protease digestion, $14 \mathrm{~min}$ at $37^{\circ} \mathrm{C}$; sample fixation to glass slide, $10 \%$ buffered formalin, $10 \mathrm{~min}$ at room temperature; dehydration in increasing concentrations of ethyl alcohol: 70, 85 and 100\% for $1 \mathrm{~min}$ each at room temperature; probe preparation; slide preparation and denaturization, $6 \mathrm{~min}$ at $80^{\circ} \mathrm{C}$; hybridization and interpretation. The slides were evaluated using chroma spectrum green filters on a Zeiss Axioskop $(\times 1000)$.

The images were captured with a COHU monochrome CCD camera and analyzed with Macprobe (Applied Imaging/PSI, Santa Clara, CA, USA). A normal nucleus hybridized with the probe displayed two yellow (orange/green) fusion signals whereas a nucleus with $\mathrm{t}(2 ; 8), \mathrm{t}(8 ; 22)$ or $\mathrm{t}(8 ; 14)$ involving a breakpoint between the hybridization targets displayed one orange, one green and one yellow (fusion) pattern. The assay was optimized using known samples of Burkitt lymphoma. A tissue microarray composed of triplicate samples from 30 reactive tonsil specimens was used to standardize the assay.

\section{In Situ Hybridization for Epstein-Barr Virus}

Latent Epstein-Barr virus infection was detected using a flourescein isothiocyanide labeled peptide nucleic acid probe for the virus (Product No. Y5200, Dako, Carpentaria, CA, USA) with a standardized in situ hybridization kit for peptide nucleic acid probes (Product No. K5201, Dako, Carpentaria, CA, USA) according to the manufacturer's instructions. A case of Hodgkin's lymphoma known to contain the virus was used as a positive control.

\section{Statistical Analysis}

Hierarchical cluster analysis

We used hierarchical clustering to analyze 39 diffuse large B-cell lymphomas for the expression of five germinal center and three activated B-cell markers. Although the software was originally designed for clustering cDNA microarray data, it also can group tumors based on immunohistochem- ical staining of tissue microarrays. ${ }^{7,8}$ Here, we used hierarchical clustering to order data in two dimensions. First, clustering software groups tumors based on the relatedness of the immunohistochemical staining using the eight antibodies; second, it groups the antibodies according to their relatedness across all the cases. After we generated the clustered data using the 'Cluster' program, we graphically displayed the information as block diagrams and dendrograms using the 'Treeview' program.' Both programs are freely available on the Internet at http://rana.lbl.gov/EisenSoftware.htm. We prepared the microarray input data files and ran the Cluster program according to the method of Liu et al. ${ }^{9}$

\section{Contour-frequency plots}

For each case, the five individual germinal center markers were summed yielding a combined germinal center score, and the three individual activated B-cell markers were summed yielding a combined activated B-cell score. Then, a two-dimensional grid was constructed with the activated B-cell values plotted along the $X$-axis and the germinal center values along the $Y$-axis. Therefore, the overall protein expression profile for each diffuse large B-cell lymphoma case could be plotted as a single (activated B-cell, germinal center) coordinate pair data point. To help visualize any clustering in the set of coordinate values, we constructed a two-dimensional contour-frequency plot, where the number of cases is proportional to the gray intensity.

\section{Other statistical methods}

We compared the distributions of data groups (clinical data and cluster data) by using either the $\chi^{2}$ test, if all expected values were 5 or greater, or the Fisher exact test. We compared means of ages between clinical groups using the unpaired $t$-test. We generated overall survival curves using the Gehan-Breslow method. Events were defined as deaths due to lymphoma, all other events (alive with disease, alive without disease, death due to other causes, no follow-up) were censored. The statistical tests were performed using SigmaStat software (Version 3.0.1, 1992-2003, SPSS Inc.).

\section{Results}

\section{Clinical Data}

We studied 39 diffuse large B-cell lymphomas: 27 non-AIDS and 12 AIDS-related. The AIDS patients were younger and tended to be more often male (see Table 2). There was no significant difference between the two groups with respect to IPI risk groups, clinical stage, number of extranodal sites, performance status, and LDH levels. The clinical follow-up ranged from 0 to 136 months, median $=15$ months. 
Table 2 Clinical features of AIDS and non-AIDS diffuse large B-cell lymphomas

\begin{tabular}{|c|c|c|c|c|}
\hline & $\begin{array}{l}\text { Total } \\
(\%)\end{array}$ & $\begin{array}{c}\text { AIDS } \\
(\%)\end{array}$ & $\begin{array}{c}\text { Non-AIDS } \\
(\%)\end{array}$ & P-value \\
\hline Total no. & 39 & 12 & 27 & \\
\hline \multicolumn{5}{|l|}{ Sex } \\
\hline Male & $24(62)$ & $10(83)$ & $14(52)$ & \multirow[t]{2}{*}{0.083} \\
\hline Female & $15(38)$ & $2(17)$ & $13(48)$ & \\
\hline \multicolumn{5}{|l|}{ Age (years) } \\
\hline Median & 54 & 38 & 70 & \multirow[t]{2}{*}{0.003} \\
\hline Range & $4-90$ & $29-70$ & $4-90$ & \\
\hline \multicolumn{5}{|l|}{ Stage } \\
\hline I/II & $19(49)$ & $7(58)$ & $12(44)$ & \multirow[t]{2}{*}{0.65} \\
\hline III/IV & $20(51)$ & $5(42)$ & $15(56)$ & \\
\hline \multicolumn{5}{|l|}{ Extranodal sites } \\
\hline Fewer than two & $26(67)$ & $8(67)$ & $18(67)$ & \multirow{2}{*}{1.0} \\
\hline Two or more & $13(33)$ & $4(33)$ & $9(33)$ & \\
\hline \multicolumn{5}{|l|}{ Performance status } \\
\hline Ambulatory & 27 (69) & $7(58)$ & $20(74)$ & \multirow[t]{2}{*}{0.455} \\
\hline Nonambulatory & $12(31)$ & $5(42)$ & $7(26)$ & \\
\hline \multicolumn{5}{|l|}{$L D H$} \\
\hline Normal & $10(26)$ & $2(17)$ & $8(30)$ & \multirow[t]{3}{*}{0.445} \\
\hline High & 27 (69) & $10(83)$ & $17(63)$ & \\
\hline Unknown & $2(5)$ & 0 & $2(7)$ & \\
\hline \multicolumn{5}{|l|}{ IPI risk group } \\
\hline Low $(0-2)^{2}$ & $21(54)$ & $6(50)$ & $15(56)$ & \multirow[t]{2}{*}{0.979} \\
\hline High (3-5) & $18(46)$ & $6(50)$ & $12(44)$ & \\
\hline
\end{tabular}

\section{Morphologic Data, Proliferation Index, C-myc} Translocation, and EBV Infection

Among the 39 diffuse large B-cell lymphomas, 30 $(77 \%)$ were subclassified as centroblastic and nine $(23 \%)$ as immunoblastic according to WHO criteria. The immunoblastic group comprised five $(42 \%)$ of the AIDS-related diffuse large B-cell lymphomas as compared to four $(15 \%)$ of the non-AIDS cases. The Ki-67 proliferation index was over $80 \%$ in $16(42 \%)$ of 38 cases: $12(46 \%)$ non-AIDS and four $(33 \%)$ AIDS-related. However, only two cases (5\%), one non-AIDS and the other AIDS-related, had a proliferation index of $100 \%$. The $c$-myc translocation was not detected in all 16 diffuse large B-cell lymphomas (six AIDS-related and 10 non-AIDS) for which FISH could be analyzed. We did not detect the EpsteinBarr virus by in situ hybridization in any of 29 diffuse large B-cell lymphomas (nine AIDS-related and 20 non-AIDS) on which results were available.

\section{Two-Dimensional Contour Plot Analysis}

The individual scores (representing percent positive cells) of the activated B-cell and germinal center markers were summed for each case (Figure 1). To visualize the overall activated B-cell and germinal center protein profile, of each case, we plotted the total activated B-cell score along the $X$-axis and the total germinal center score along the $Y$-axis on a two-dimensional grid. After all of the cases were plotted as individual coordinate $X, Y$ data points, we constructed two-dimensional contourfrequency plots (see Figure 2a-c). We have shown that this method clearly separates Burkitt lymphoma cases from diffuse large B-cell lymphoma cases. ${ }^{10}$

Initially, the AIDS-related and non-AIDS diffuse large B-cell lymphomas were evaluated using separate contour plots. The two-dimensional contour-frequency plot of non-AIDS diffuse large B-cell lymphomas (Figure 2a) showed two distinct clusters: cluster 1 with a high germinal center phenotype and cluster 3 with a high activated B-cell phenotype. In contrast, the AIDS-related diffuse large B-cell lymphomas (Figure $2 \mathrm{~b}$ ) tended to form a single aggregate (cluster 2). Next, we superimposed the contour plots of the AIDS-related and the non-AIDS cases (Figure 2c), which demonstrated that the predominantly AIDS-related cases of cluster 2 displayed an intermediate germinal center/activated B-cell phenotype compared to clusters 1 and 3 (predominantly nonAIDS) Thus, the AIDS status of the patient predicted the immunophenotype of the diffuse large B-cell lymphoma $(P=0.02$, Fisher exact test).

The scores of individual markers across the three clusters so defined are visualized in Figure 2e. These clusters did not correlate with the morphologic subtype, nor did they show differences in the Ki-67 proliferation index (mean values of 1.10, 1.18 and 1.44 for clusters 1,2 , and 3, respectively; Figure 2e). Among the remaining nine outlying cases, seven $(18 \%)$ had low total germinal center and low to intermediate total activated B-cell scores, which suggest that they may belong to the so-called Type 3 group of diffuse large B-cell lymphomas. ${ }^{2}$ Among the markers studied, the expression of CD138 was restricted to a single case, an outlier with a maximum activated B-cell score which did not contribute to the analysis.

\section{Survival Curves-Clusters 1, 2, and 3}

We next investigated the overall survival of AIDS vs non-AIDS patients with diffuse large B-cell lymphoma by comparing the survival curves for each of the three germinal center/activated B-cell clustered lymphoma phenotypes using the Gehan-Breslow method (Figure 2d). While our results did not reach statistical significance owing to the limited study power, we did observe the following trends. The non-AIDS patients in cluster 1 tended to have a superior overall survival while the non-AIDS patients in cluster 3 appeared to show a poor OS. However, the AIDS patients in cluster 2 tended to have an intermediate overall survival.

\section{Hierarchical Clustering}

Individual antigen scores were analyzed using the Cluster and Treeview programs (as described 

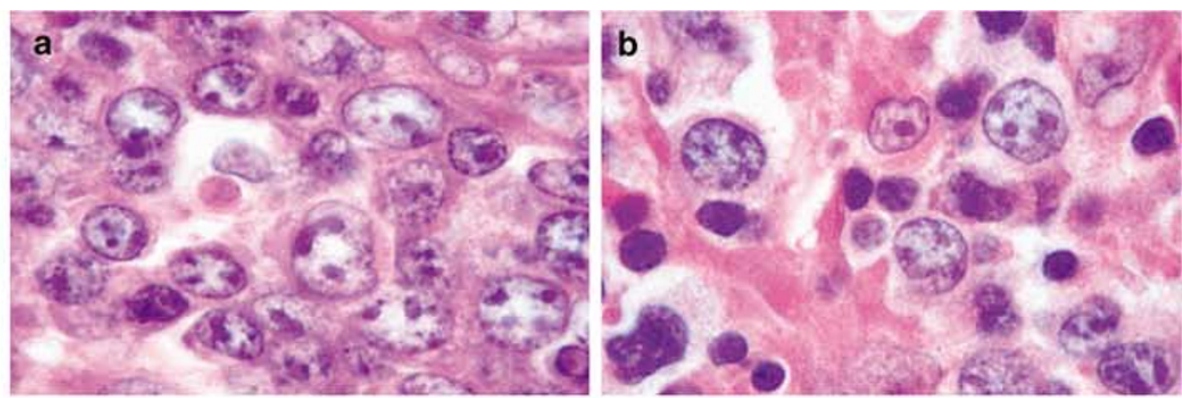

Activated B-cell markers
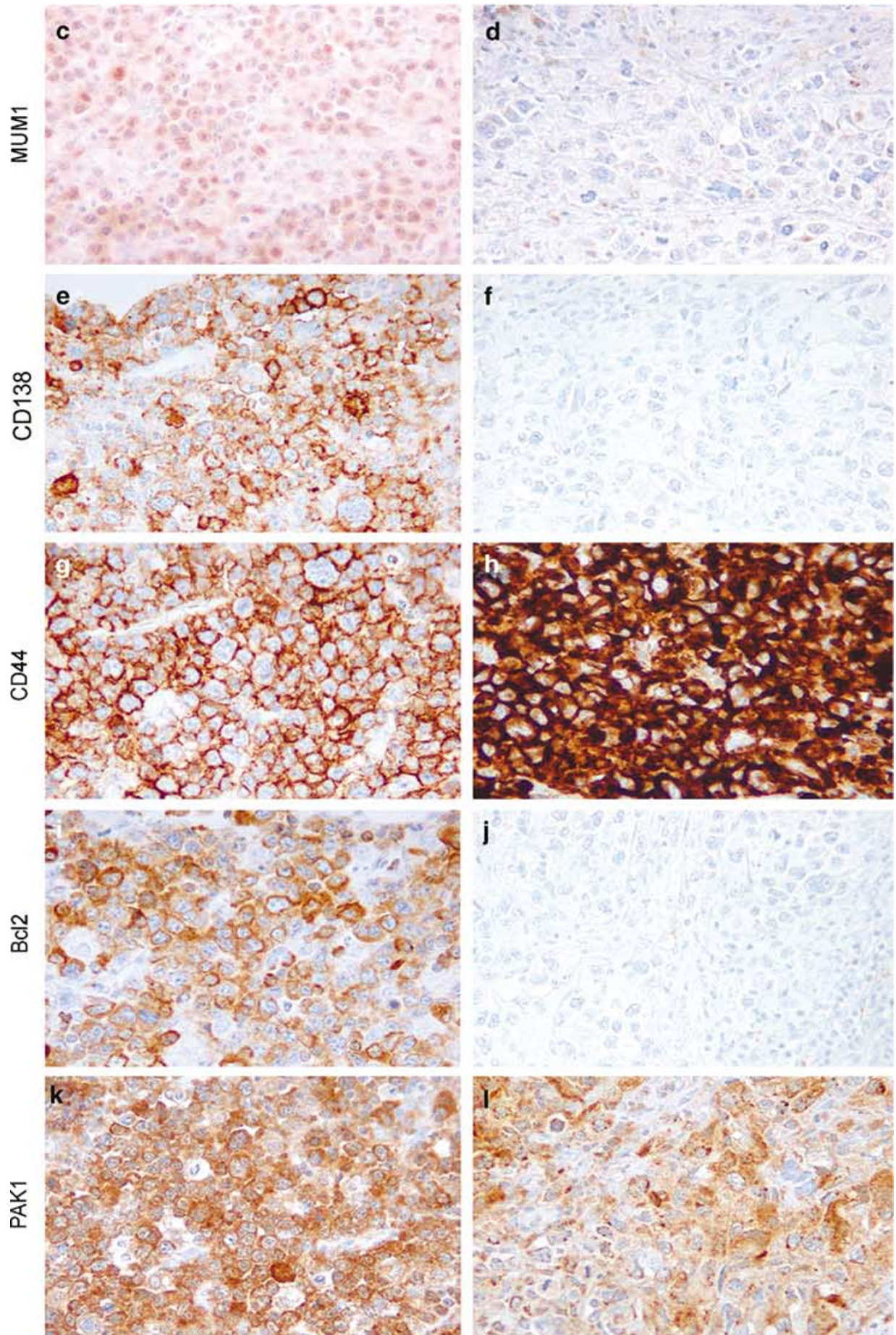


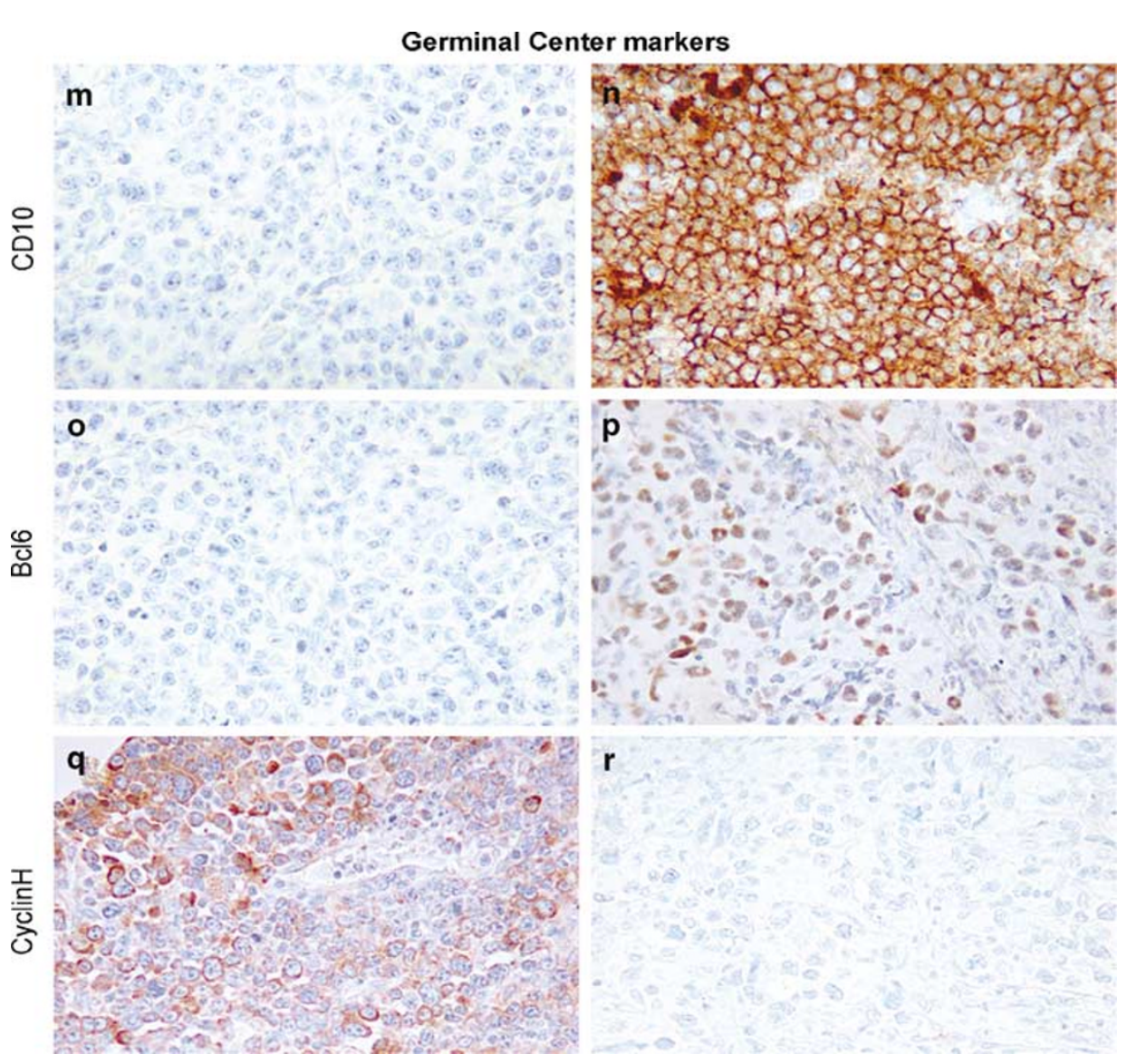

Figure 1 Continued.

above). The resulting clusters did not correlate with AIDS status or morphologic subtype nor did they demonstrate varying survival patterns (data not shown).

\section{Comparison with 3 Marker Immunophenotype}

Recently, Hans et $a l^{3}$ developed a three immunostain system (MUM1, BCL6, CD10) to classify nonAIDS diffuse large B-cell lymphomas as either germinal center or non-germinal center phenotype, which correlated with overall survival. When we applied this system to our non-AIDS cases, we found the cases in cluster 1 scored as a germinal center phenotype whereas those in cluster 3 scored as a non-germinal center phenotype $(P=0.003$, Fisher exact test). Therefore, these results are in good agreement with our own two-dimensional contour-frequency plot method.

\section{Discussion}

Diffuse large B-cell lymphomas were originally categorized into prognostically favorable and unfavorable types based on cDNA gene expression profiles which recapitulated germinal center B cells and activated peripheral blood B-cells. ${ }^{1}$ Initially the results of an oligonucleotide-based microarray study of gene expression did not predict survival based on the germinal center and activated B-cell categorization, ${ }^{11}$ but subsequent work did confirm the prognostic utility of classifying diffuse large B-cell lymphomas into germinal center and non-germinal center types. ${ }^{12}$ In all, 14 genes, which were present on both the cDNA and oligonucleotide microarrays, could predict clinical behavior based on distinct molecular types. ${ }^{12}$ Gene expression studies have also identified a so-called Type 3 group of diffuse large B-cell lymphomas with poor survival. ${ }^{2}$ Investigations to identify further subgroups have deter-

Figure 1 Two representative cases of morphologically similar diffuse large B-cell lymphomas. Case 1 (a), in the left column, has an activated B-cell phenotype with an activated B-cell marker score of $2(\mathrm{c})+2(\mathrm{e})+2(\mathrm{~g})+2(\mathrm{i})+2(\mathrm{k})=10$ and a germinal center marker score of $0(\mathrm{~m})+0(\mathrm{o})+2(\mathrm{q})=2$. In contrast, case $2(\mathbf{b})$, in the right column, has a germinal center phenotype with an activated B-cell marker score of $0(\mathrm{~d})+0(\mathrm{f})+2(\mathrm{~h})+0(\mathrm{j})+0(\mathrm{l})=2$ and a germinal center marker score of $2(\mathrm{n})+2(\mathrm{p})+0(\mathrm{r})=4$. Only percent positive cells were scored, not staining intensity (hematoxylin and eosin at $\times 1000$ magnification, immunoperoxidase at $\times 200$ magnification). 

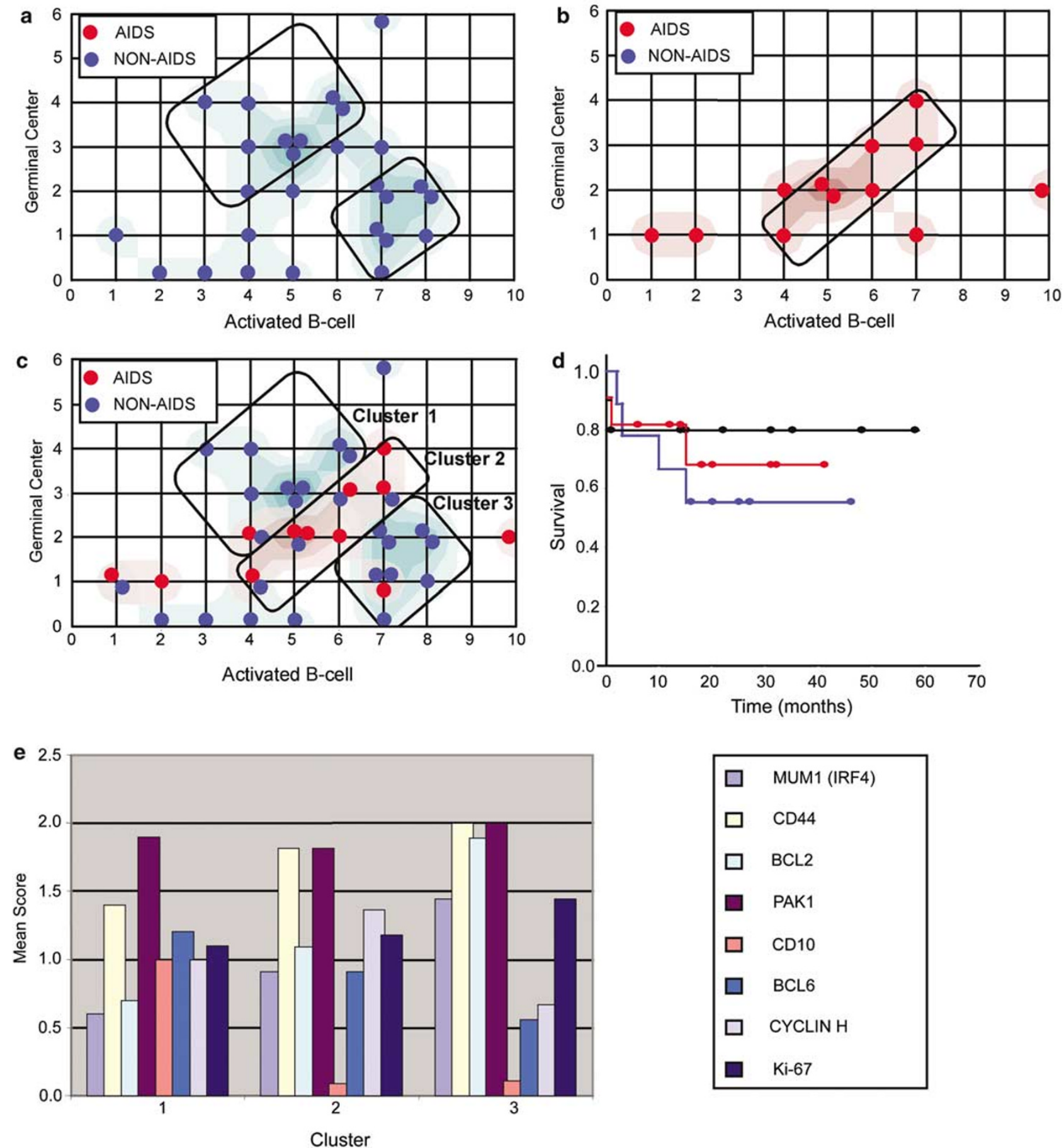

Figure 2 (a) Two-dimensional contour plot of non-AIDS diffuse large B-cell lymphomas. (b) Two-dimensional contour plot of AIDS-related diffuse large B-cell lymphomas. (c) Superimposed two-dimensional contour plots of non-AIDS and AIDS-related diffuse large B-cell lymphomas. (d) Survival curves of clusters 1 (black), 2 (red), and 3 (blue) (Gehan-Breslow method). (e) Comparison of individual markers and Ki-67 scores between the three clusters (as CD138 was not expressed by any of the cases in the three clusters, it was excluded from this chart).

mined that primary mediastinal B-cell lymphomas form a distinct group with similarity to Hodgkin's lymphoma. ${ }^{13,14}$ Although additional subgroups within the germinal center diffuse large B-cell lymphomas based on the presence or absence of $\mathrm{t}(14 ; 18)(\mathrm{q} 32 ; \mathrm{q} 21)$ have been defined, these did not predict survival. ${ }^{15}$ Recently, an alternate approach, based on clustering of whole genome arrays has identified three new groups among diffuse large Bcell lymphomas: 'oxidative phosphorylation', 'B-cell receptor/proliferation', and 'host response', but these results were not associated with prognosis. ${ }^{16}$ 
Protein expression studies have also been successfully used to distinguish biologically and prognostically significant groups of diffuse large B-cell lymphomas. By combining the IPI score, BCL2 positivity and germinal center phenotype, $85 \%$ of 177 patients could be stratified into favorable and poor risk groups. ${ }^{17}$ Another study defined four biologic subgroups (germinal center with and without CD10, postgerminal center and plasmablastic) that did not prognosticate survival. ${ }^{18}$ Later, it was shown that only three (CD10, BCL6, MUM1) or four (CD10, BCL6, CD138, MUM1) protein markers could accurately predict overall survival. ${ }^{3,4}$ Additionally, the expression of the winged helix transcription factor Forkhead box-P1 has been shown to identify a subgroup of patients with especially poor prognosis among the non-germinal center type diffuse large B-cell lymphomas. ${ }^{19}$

Prior to the introduction of highly active antiretroviral therapy, the incidence of AIDS-related non-Hodgkin's lymphomas was 60-200 times more frequent in AIDS patients compared to immunocompetent individuals. ${ }^{20-22}$ With the advent of highly active antiretroviral therapy, the incidence of AIDSrelated non-Hodgkin's lymphomas has declined. ${ }^{23-25}$ A meta-analysis of 23 cohort studies (involving 47936 seropositive individuals) showed reduced incidence rates from 1992-1996 (6.2 per 1000 person-years) to 1997-1999 (3.6 per 1000 personyears). ${ }^{23}$ Part of this reduction may be due to improved CD4 cell counts. ${ }^{24}$ Despite the three-fold increase in survival of patients with AIDS-related lymphomas, the prognosis still appears worse than HIV-negative patients with comparable disease. ${ }^{24,26,27}$

It is unclear whether these differences between AIDS-related and non-AIDS diffuse large B-cell lymphomas reflect biological variations in the lymphoma itself, or in the immunodeficient host, or in both. A definitive understanding of the pathogenesis of AIDS-related diffuse large B-cell lymphomas is still lacking. General models of chronic antigen stimulation, immunosuppression, cytokine dysregulation, and genetic changes have been proposed; some genetic alterations including rearrangements of $B C L 6$, a zinc-finger transcriptional repressor and aberrant somatic hypermutation, have been reported in both AIDS and non-AIDS diffuse large B-cell lymphomas. ${ }^{28-31}$ Epstein-Barr viral infection has been reported in 30 and $80-90 \%$ of the centroblastic and immunoblastic variants of AIDS-related diffuse large B-cell lymphomas, respectively. ${ }^{22,31}$

In contrast to diffuse large B-cell lymphoma in immunocompetent patients, there are only a limited number of gene expression profiling studies of AIDS-related diffuse large B-cell lymphoma. One group, using PCR-based suppression subtractive hybridization, determined that lymph-node-based AIDS-related diffuse large B-cell lymphoma overexpressed the proto-oncogene TCL1 (T-cell leukemia-1), which was absent in non-AIDS diffuse large B-cell lymphoma. ${ }^{32}$ The authors postulated that the deleterious effects of HIV on the host immune system could be responsible for the different clinical outcomes in AIDS vs non-AIDS patients with lymphoma. ${ }^{20,32,33}$ In the context of B-lymphocyte development, an early immunohistochemical study of AIDS-related lymphomas proposed three phenotypic patterns corresponding to centroblasts, late germinal center/early postgerminal center B cells, and postgerminal center Bcells. ${ }^{34}$ Another study, which included cases of both AIDS-related diffuse large B-cell lymphoma and Burkitt lymphoma, has suggested that there may be a shift away from the more chemoresistant lymphomas of postgerminal center origin because of the better immune function conferred by highly active antiretroviral therapy. ${ }^{26}$

In the present pilot study, we focused solely on diffuse large B-cell lymphomas. We found that AIDS-related diffuse large B-cell lymphomas occurred in younger patients and displayed immunoblastic morphology more often than non-AIDS cases. Using two-dimensional contour plots, the non-AIDS diffuse large B-cell lymphomas clustered into distinct germinal center and activated B-cell types similar to reports by others. ${ }^{1,3,4}$ We found significant correlation between the germinal center and nongerminal center groups (defined using the three immunostain method described by Hans et $a l^{3}$ ) and the germinal center and activated B-cell clusters using two-dimensional contour plots, which further validates this new method. We report the new observation that the AIDS-related diffuse large B-cell lymphomas formed a single cluster with an intermediate germinal center activated B-cell phenotype, suggesting a unique pathophysiology.

After the three AIDS and non-AIDS clusters were defined by this method, nine outlying cases remained, seven $(17.9 \%)$ of which displayed low germinal center scores and low to intermediate activated B-cell scores. We postulate that these may belong to the 'Type 3' group of diffuse large B-cell lymphomas, which lack either a germinal center or activated B-cell signature and range between 17 and $21.7 \%$ of cases in published studies. ${ }^{2,12}$

While we observed that the overall survival of patients with AIDS-related diffuse large B-cell lymphomas tends to be intermediate, between those of the non-AIDS individuals in the germinal center and activated B-cell clusters, these findings need to be borne out by future studies with larger data sets and long-term follow-up. In addition, the impact of highly active antiretroviral therapy and chemotherapy requires investigation.

\section{References}

1 Alizadeh AA, Eisen MB, Davis RE, et al. Distinct types of diffuse large B-cell lymphoma identified by gene expression profiling. Nature 2000;403: 503-511. 
2 Rosenwald A, Wright G, Chan WC, et al. The use of molecular profiling to predict survival after chemotherapy for diffuse large-B-cell lymphoma. N Engl J Med 2002;346:1937-1947.

3 Hans CP, Weisenburger DD, Greiner TC, et al. Confirmation of the molecular classification of diffuse large B-cell lymphoma by immunohistochemistry using a tissue microarray. Blood 2004;103:275-282.

4 Chang CC, McClintock S, Cleveland RP, et al. Immunohistochemical expression patterns of germinal center and activation B-cell markers correlate with prognosis in diffuse large B-cell lymphoma. Am J Surg Pathol 2004;28:464-470.

5 Gatter KC, Warnke RA. Diffuse large B-cell lymphoma. In: Harris NL, Jaffe ES, Stein H, Vardiman JW (eds). World Health Classification of Tumors: Pathology and Genetics of Tumors of Hematopoietic and Lymphoid Tissues. IARC Press: Lyon, 2001, pp 171-174.

6 The International Non-Hodgkin's Lymphoma Prognostic Factors Project. A predictive model for aggressive non-Hodgkin's lymphoma. N Engl J Med 1993;329: 987-994.

7 Eisen MB, Spellman PT, Brown PO, et al. Cluster analysis and display of genome-wide expression patterns. Proc Natl Acad Sci USA 1998;95:14863-14868.

8 Hsu FD, Nielsen TO, Alkushi A, et al. Tissue microarrays are an effective quality assurance tool for diagnostic immunohistochemistry. Mod Pathol 2002; 15:1374-1380.

9 Liu CL, Prapong W, Natkunam Y. Software tools for high-throughput analysis and archiving of immunohistochemistry staining data obtained with tissue microarrays. Am J Pathol 2002;161:1557-1565.

10 Gormley R, Madan R, Dulau A, et al. Germinal Center and Activated B-cell profiles separate Burkitt lymphoma and diffuse large B-cell lymphoma in AIDS and non-AIDS cases. Am J Clin Pathol 2005;124: 790-798.

11 Shipp MA, Ross KN, Tamayo P, et al. Diffuse large Bcell lymphoma outcome prediction by gene-expression profiling and supervised machine learning. Nat Med 2002;8:68-74.

12 Wright G, Tan B, Rosenwald A, et al. A gene expression-based method to diagnose clinically distinct subgroups of diffuse large B cell lymphoma. Proc Natl Acad Sci USA 2003;100:9991-9996.

13 Rosenwald A, Wright G, Leroy $\mathrm{K}$, et al. Molecular diagnosis of primary mediastinal B cell lymphoma identifies a clinically favorable subgroup of diffuse large B cell lymphoma related to Hodgkin lymphoma. J Exp Med 2003;198:851-862.

14 Savage KJ, Monti S, Kutok JL, et al. The molecular signature of mediastinal large B-cell lymphoma differs from that of other diffuse large B-cell lymphomas and shares features with classical Hodgkin lymphoma. Blood 2003;102:3871-3879.

15 Iqbal J, Sanger WG, Horsman DE, et al. BCL2 translocation defines a unique tumor subset within the germinal center B-cell-like diffuse large B-cell lymphoma. Am J Pathol 2004;165:159-166.

16 Monti S, Savage KJ, Kutok JL, et al. Molecular profiling of diffuse large B-cell lymphoma identifies robust subtypes including one characterized by host inflammatory response. Blood 2005;105:1851-1861.

17 Barrans SL, Carter I, Owen RG, et al. Germinal center phenotype and bcl-2 expression combined with the International Prognostic Index improves patient risk stratification in diffuse large B-cell lymphoma. Blood 2002;99:1136-1143.

18 Colomo L, Lopez-Guillermo A, Perales $\mathrm{M}$, et al. Clinical impact of the differentiation profile assessed by immunophenotyping in patients with diffuse large B-cell lymphoma. Blood 2003;101:78-84.

19 Barrans SL, Fenton JA, Banham A, et al. Strong expression of FOXP1 identifies a distinct subset of diffuse large B-cell lymphoma (DLBCL) patients with poor outcome. Blood 2004;104:2933-2935.

20 Patrone L, Henson SE, Teodorovic J, et al. Gene expression patterns in AIDS vs non-AIDS-related diffuse large B-cell lymphoma. Exp Mol Pathol 2003;74:129-139.

21 Knowles DM, Pirog EC. Pathology of AIDS-related lymphomas and other AIDS-defining neoplasms. Eur J Cancer 2001;37:1236-1250.

22 Raphael M, Borisch B, Jaffe ES. Human Immunodeficiency virus-related lymphomas. In: Harris NL, Jaffe ES, Stein H, Vardiman JW (eds). World Health Classification of Tumors: Pathology and Genetics of Tumors of Hematopoietic and Lymphoid Tissues. IARC Press: Lyon, 2001, pp 260-263.

23 International Collaboration on HIV and Cancer. Highly active antiretroviral therapy and incidence of cancer in human immunodeficiency virus-infected adults. J Natl Cancer Inst 2000;92:1823-1830.

24 Besson C, Goubar A, Gabarre J, et al. Changes in AIDSrelated lymphoma since the era of highly active antiretroviral therapy. Blood 2001;98:2339-2344.

25 Wolf T, Brodt HR, Fichtlscherer S, et al. Changing incidence and prognostic factors of survival in AIDSrelated non-Hodgkin's lymphoma in the era of highly active antiretroviral therapy (HAART). Leuk Lymphoma 2005;46:207-215.

26 Little RF, Pittaluga S, Grant N, et al. Highly effective treatment of acquired immunodeficiency syndromerelated lymphoma with dose-adjusted EPOCH: impact of antiretroviral therapy suspension and tumor biology. Blood 2003;101:4653-4659.

27 Fisher RI, Gaynor ER, Dahlberg S, et al. Comparison of a standard regimen (CHOP) with three intensive chemotherapy regimens for advanced non-Hodgkin's lymphoma. N Engl J Med 1993;328:1002-1006.

28 Gaidano G, Capello D, Carbone A. The molecular basis of acquired immunodeficiency syndrome-related lymphomagenesis. Semin Oncol 2000;27:431-441.

29 Gaidano G, Pasqualucci L, Capello D. Aberrant somatic hypermutation in multiple subtypes of AIDS-associated non-Hodgkin lymphoma. Blood 2003;102:1833-1841.

30 Knowles DM. Etiology and pathogenesis of AIDSrelated non-Hodgkin's lymphoma. Hematol Oncol Clin North Am 2003;17:785-820.

31 Aboulafia DM, Pantanowitz L, Dezube BJ. AIDSrelated non-Hodgkin lymphoma: still a problem in the era of HAART. AIDS Read 2004;14:605-617.

32 Teitell M, Damore MA, Sulur GG, et al. TCL1 oncogene expression in AIDS-related lymphomas and lymphoid tissues. Proc Natl Acad Sci USA 1999;96:9809-9814.

33 Said JW, Hoyer KK, French SW, et al. TCL1 oncogene expression in B cell subsets from lymphoid hyperplasia and distinct classes of B cell lymphoma. Lab Invest 2001;81:555-564.

34 Carbone A, Gloghini A, Larocca LM, et al. Expression profile of MUM1/IRF4, BCL-6, and CD138/syndecan-1 defines novel histogenetic subsets of human immunodeficiency virus-related lymphomas. Blood 2001;97: 744-751. 